\title{
Investigating the Rheological Properties of Ultra High Strength Concrete Made with Various Superplasticizers
}

\author{
Anthony Torres ${ }^{1}$, Federico Aguayo ${ }^{1}$, Srinivas Allena ${ }^{2}$, Michael Ellis ${ }^{1}$ \\ 1. Texas State University, San Marcos, TX, 78666, USA \\ 2. Cleveland State University, Cleveland, 4415, USA \\ E-mail: ast36@txstate.edu
}

\begin{abstract}
Ultra-High Strength Concrete (UHSC) is a high-strength and highly ductile material formulated to provide compressive strengths exceeding 130MPa. UHSC materials typically have a very low water-tocementitious ratio $(\mathrm{w} / \mathrm{cm})$, which requires the use of superplasticizers to disperse the fine particles and to make the material workable for placing, handling and consolidating. Common examples of superplasticizer compositions include Polynaphthalene Sulfonate (PNS), Polymelamine Sulfonate (PMS) and Polycarboxylate Ether (PCE) based polymers. This study focuses on assessing the impact of various superplasticizers on the compressive strength and rheological performance of a UHSC mixture. Four different types of superplasticizers were used; two different PCE based superplasticizers from a leading manufacturer, one PNS superplasticizer, and one PCE superplasticizer, both of which were provided by a local chemical provider. Specific properties assessed were the superplasticizers' viscosity, concrete workability through the mortar-spread test, concrete rheology, and 7, 14, and 28 day compressive strengths. Two mixtures were produced with two w/cm $(0.20$ and 0.15$)$, which would subsequently increase the amount of HRWRA needed, from $34.7 \mathrm{~L} / \mathrm{m}^{3}$ to $44.5 \mathrm{~L} / \mathrm{m}^{3}$. The results show that both name brand PCE superplasticizers produce a higher spread, lower viscosity, and a higher compressive strength at all ages tested up to 28 days than the two local superplasticizers. Additionally, the rheology test demonstrated that the name brand PCE superplasticizers, and UHSC produced with such superplasticizers, had a lower viscosity at all angular speeds than the local superplasticizers counterparts.
\end{abstract}

Keywords: Ultra high strength concrete; Workability; Superplasticizers.

\section{Introduction}

The technology development of concrete and demand for high strength construction materials gives momentum to the development of Ultra-High Strength Concrete (UHSC). UHSC is a high-strength and highly ductile material formulated to provide compressive strengths exceeding $130 \mathrm{MPa}$. However, some current UHSC preparation methods require costly materials and relatively sophisticated technology. UHSC mixtures consist of Portland cement, fine aggregate, and steel fibers. UHSC components also often require the addition of materials such as supplementary cementing material (e.g., silica fume and quartz flour) and superplasticizers for increased workability and high early-age strength. These specialized materials contribute to the increase in compressive and tensile strength as well as durability properties. Superplasticizers are chemical additives, which allow cement particles to disperse more effectively within a mixture allowing for improved workability and achieving increased density of the cement matrix. Increasing density and improving particle distribution in a cement slurry usually generates higher compressive strength after curing through improved particle packing of constituents. Lastly, the addition of steel fibers helps to improve the ductile behavior of this material increasing the capacity to deform and support flexural and tensile loads, even after initial cracking. Using UHSC for construction is simplified by the elimination of reinforcing steel and the ability of the material to be virtually self-placing or dry cast.

Superplasticizers are used in fresh concrete to modify the rheological properties. High range water reducing admixtures (HRWR) are a particular class of superplasticizers, which are used to manipulate the rheological profile of a concrete slurry. High range water reducing admixture requirements are outlined by ASTM C494 "Standard Specifications for Admixtures in Concrete" [1]. Several chemical additives can meet ASTM requirements for high range water reducing admixtures. Common examples of HRWR additives include Polynaphthalene Sulfonate (PNS), Polymelamine Sulfonate (PMS) and Polycarboxylate Ether (PCE) based polymers. These chemicals are all used to disperse cement particles and increase flowability of the slurry. The effectiveness of a water reducer is a result of the chemical structure; some variations in polymer-based superplasticizers include charge density differentiation, side chain length, main backbone length, degree of backbone polymerization and composition of functional groups.

This study focuses on assessing the impact of various superplasticizers on the performance of UHSC. Four different types of superplasticizers were used; two different PCE based superplasticizers from a leading 
manufacturer (PCE Name Brand 1, PCE Name Brand 2), one PNS superplasticizer, and one PCE superplasticizer (PCE Local Provider), both of which were provided by a local chemical provider. The local provided products are believed to provide similar end results to the name brand products at a cheaper cost to the consumer. This study aims at elucidated the effect that different types of superplasticizers have on the rheological and compressive strength performance of UHSC. In order to measure the viscosity of the UHSC in this study, the workability was measured via the mortar spread test. A viscometer was used to compare the viscous properties of the different UHSC mixtures with various superplasticizers. The stress and strain of the UHSC mixtures were measured with a dynamic shear rheometer (DSR), which characterizes both viscous and elastic behavior by measuring the complex shear modulus and phase angle of materials.

\section{Background information}

The effect of different types of superplasticizer on fresh, rheological and strength properties of selfconsolidating concrete (SCC) was investigated by Mardani-Aghabaglou et al. [2]. The admixtures used had the same main chain and the same polymer structure but different molecular weight and different side chain density of carboxylic acid groups. Molecular side chains of a polymer can be visualized as branches of a tree where the main chain is the tree trunk. The author summarizes how the dispersion mechanism of PCE (polycarboxylate)based superplasticizers is more related to a steric hindrance effect produced by the presence of neutral sidelong graft chains. The dispersion from PNS and PMS type superplasticizers is shown to be caused by the presence of negatively charged anionic groups which are responsible for the adsorption of the polymers on the surface of cement particles. The study indicates better dispersion with high molecular weight PC with large side chains (similar to a tall tree with many large branches). Fresh concrete properties of the SCC mixtures were measured by using the slump flow, V-funnel and L-box tests as well as slump-flow loss after 15 and 30 min. The rheological parameters including apparent yield strength and plastic viscosity were measured by an impeller type rheometer suitable for SCC mixtures. These tests were performed in accordance with European Federation of National Associations Representing for Concrete (EFNARC), which is the authoritative voice of contractors, manufacturers, raw material suppliers and consultants in the specialized construction and concrete systems industry. The hardened samples were cast in $150 \mathrm{~mm}$ cubic molds. The specimens were demolded after 24 hour and were stored in a moist room in water at $23 \pm 2^{\circ} \mathrm{C}$ until the testing day. For each mixture, twelve specimens were prepared and tested at 1 , 3, 7 and 28-day ages for compressive strength in accordance with EN 12390-3 standard. The ultrasonic pulse velocity (UPV) values of the concrete mixtures were determined in accordance with the ASTM C597 Standard Test Method for Pulse Velocity Through Concrete at the same ages. The dynamic elastic modulus was calculated using the UPV assuming constant Poisson ratio. The data shows that the dynamic modulus increased with age due to lower mass and UPV values.

M. Collepardi et al. [3] completed a study to optimize the type and dosage of superplasticizer in concretes incorporating ASTM C618 Class F fly ash to reach compressive strengths as high as those of superplasticized silica fume concretes. Two types of HRWRAs based on sulfonated naphthalene polymer (SNP) and sulfonated melamine polymer (SMP) both as 40 percent aqueous solution have been used in the presence of fly ash or silica fume to manufacture superplasticized flowing concretes containing ASTM C150 Type I or Type III Portland cements. The superplasticizer dosage and the pozzolan addition ranged from the 2 to 4 percent and from 12 to 20 percent, respectively. The cement factor varied from 255 to $400 \mathrm{~kg} / \mathrm{m} 3$. The results of the investigation work indicate that only in the presence of ASTM C150 Type III Portland cement, superplasticized fly ash concrete can be as strong as the corresponding silica fume concrete, particularly at relatively high cement factors $(300 \mathrm{~kg} / \mathrm{m} 3)$. The author shows that it is possible to manipulate particle size to generate high strength cement. This is accomplished by changing the ratios of silica fume, dispersant, fly ash and Portland cement.

\section{Experimental program}

\subsection{Materials and mixture design}

Type I/II Portland cement was used in the preparation of all concrete mixtures that conforms to ASTM C150 Standard Specification for Portland Cement [4]. A densified dry powder microsilica supplementary cementitious material (SCM) was also used in producing UHSC mixtures. The small particle size of silica fume can improve particle packing and dramatically increase strengths in high strength concrete. River sand was collected and processed over a \#30 sieve. Once the sieved fine aggregate was obtained, the sand was washed over a \#200 sieve to remove any remaining micro fine particles from the aggregate. After washing, the aggregate was dried in the oven at $110^{\circ} \mathrm{C}$ for 24 plus/minus 4 hours and stored in a container prior to mixing. Two UHCS mixtures were designed based on recommendations of the literature $[3,5,6]$ with two different w/c ratios to determine the impact of the amount of superplasticizer on UHSC performance. The mixture designs can be seen in Table 1. Information regarding the superplasticizers can be found inn Table 2. 
Table 1. Mixture proportions

\begin{tabular}{lcc}
\hline Constituents & $\mathrm{w} / \mathrm{cm}=0.20\left(\mathrm{~kg} / \mathrm{m}^{3}\right)$ & $\mathrm{w} / \mathrm{cm}=0.15\left(\mathrm{~kg} / \mathrm{m}^{3}\right)$ \\
\hline Type I/II Portland Cement & 889 & 889 \\
Silica Fume & 222 & 222 \\
Fine Sand & 833 & 1009 \\
HRWRA & $34.7\left(\mathrm{~L} / \mathrm{m}^{3}\right)$ & $44.6\left(\mathrm{~L} / \mathrm{m}^{3}\right)$ \\
Water & 229 & 166 \\
\hline
\end{tabular}

Table 2. Properties of the superplasticizers

\begin{tabular}{lllll}
\hline Appearance & $\begin{array}{l}\text { PCE NB* } \\
\text { (Yellowish } \\
\text { Liquid) }\end{array}$ & $\begin{array}{l}\text { PCE NB*2 } \\
\text { (Yellowish } \\
\text { Liquid) }\end{array}$ & $\begin{array}{l}\text { PNS } \\
\text { (Gold/Brownish } \\
\text { Liquid) }\end{array}$ & $\begin{array}{l}\text { PCE LP** } \\
\text { (Yellowish Liquid) }\end{array}$ \\
\hline $\mathrm{pH}, 25^{\circ} \mathrm{C}$ & 6.10 & 6.06 & 6.20 & 6.12 \\
Density $\left(\mathrm{g} / \mathrm{cm}^{3}\right)$ & 1.12 & 1.10 & 1.07 & 1.10 \\
Mass average molecular weight & 50,000 & 49,000 & 42,000 & 50,000 \\
Side chain density of carboxylic & $1: 5$ & $1: 4$ & $1: 6.5$ & $1: 5$ \\
acid groups & & & & \\
${ }^{*} \mathrm{NM}=$ Name Brand; **LP = Local Provider & &
\end{tabular}

\subsection{Sample Preparation}

The constituents of each mixture were then mixed for approximately 20 minutes using a laboratory pan mixer. The dry constituents (aggregate, cement, and silica fume) were mixed for the first 2 minutes and then $75 \%$ of the water was added. After thorough mixing, the specific superplasticizer was added with the remaining $25 \%$ of the water. This preparation method was used based on the literature and experience $[3,5,6]$. In order to minimize as many variables as possible, one curing regimen was tested for the compression testing samples, which was selected based on the literature review developed by Shaheen and Shrive [7]. This curing regimen consists first of curing the samples at room temperature $23^{\circ} \mathrm{C}\left(73^{\circ} \mathrm{F}\right)$ for the first 24 hours. After demolding, the specimens were then heat cured in a water bath at $50 \circ \mathrm{C}(122 \circ \mathrm{F})$ until 2 days prior to testing. At two days prior to testing, the specimens were removed from the water bath and dry cured at $200 \circ \mathrm{C}(392 \circ \mathrm{F})$. The dry curing was added based on recommendation from the literature review [8], such that a high dry curing 2 days prior to testing accelerates strength gain.

Compressive strength specimens were molded using 50-mm (2-in.) cube molds. All samples were compacted according to the mortar cube compaction method described in ASTM C109 [9] Compressive Strength of Hydraulic Cement Mortars. Cubes specimens were used to avoid problems with end preparation of cylindrical specimens [5]. After the specimens were properly cured, they were individually tested according to BS 12390-3-2009 [10]. The British Standard was used as it provides greater detail to testing hardened concrete cubes in compression than ASTM C 39-15a [10]. An average of three samples was tested per data point reported in the results section.

\subsection{Testing equipment}

For the purposes of testing the mortar flow (spread) ASTM C1437-15 [11] was followed. A flow table, caliper, tamper, trowel, and straightedge were used in accordance to the standard. The flow testing was completed immediately following mixing of the concrete was complete.

Both the individual superplasticizer and the mixed concrete was investigated for their rotational viscosity using a Brookfield model DV-II+ rotational viscometer. This type of apparatus is normally used to characterize asphalt binders, however this equipment was used to determine the viscosity (in centipoises, $\mathrm{cP}$ ) of superplasticizers and the mixed UHSC at different angular speeds. The viscometer operates by rotating a spindle inside the specimen test tube and measuring the torque required to rotate the spindle at the provided speed.

\section{Results}

The shear resistance of each superplasticizer was measured at 3 different rates (20, 50 and $100 \mathrm{rpm})$ shown in Fig. 1. Observing the superplasticizer fluids response to shear at different rates helps to identify the effect of the superplasticizer on the flow and strength of the UHPC mixtures. The spread flow results can be seen in Table 2.

The spread flow results on each mixture can be seen in Table 3 .

It can be seen in both Figure 1 and Table 3 that the viscosity of the superplasticizers used has a direct effect on the flow results of the mixtures. In other words, the PCE provided by a local provider had the highest viscosity produced in the Brookfield rheometer, and the UHSC mixtures produced with the locally provided PCE had the lowest spread. Although the superplasticizers are marketed as comparable products there appears to be a compositional difference that is having an effect on the spread of the UHSC. Although both manufactures do not publish their exact chemical composition of percent dissolved solids in solutions for their superplasticizers, this 
study aims to simply elucidate the direct effect of each on the performance of two UHSC mixtures. It can also be seen in Table 3 that, although there is an increase in superplasticizer amount from the $\mathrm{w} / \mathrm{cm}=0.20$ mixtures to the $\mathrm{w} / \mathrm{cm}=0.15$, the spread flow results are still reduced for the $\mathrm{w} / \mathrm{cm}=0.15$ mixtures.

The results of the viscosity of the UHSC mixtures made with the four superplasticizers can be seen in Fig 2 and fig. 3 .

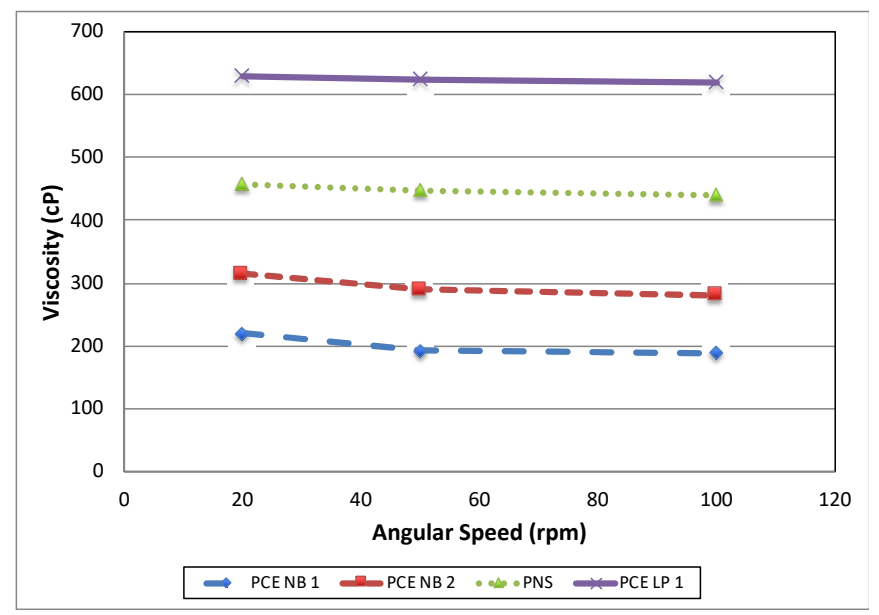

Figure 1. Viscosity of Superplasticizers at various rotational speeds.

Table 3. Spread flow results.

\begin{tabular}{lcc}
\hline Superplasticizer & $\mathrm{w} / \mathrm{cm}=0.20(\mathrm{~mm})$ & $\mathrm{w} / \mathrm{cm}=0.15(\mathrm{~mm})$ \\
\hline PCE NB 1 & 201.2 & 186.7 \\
PCE NB 2 & 197.9 & 181.6 \\
PNS & 167.1 & 159.3 \\
PCE LP & 162.6 & 154.2 \\
\hline
\end{tabular}

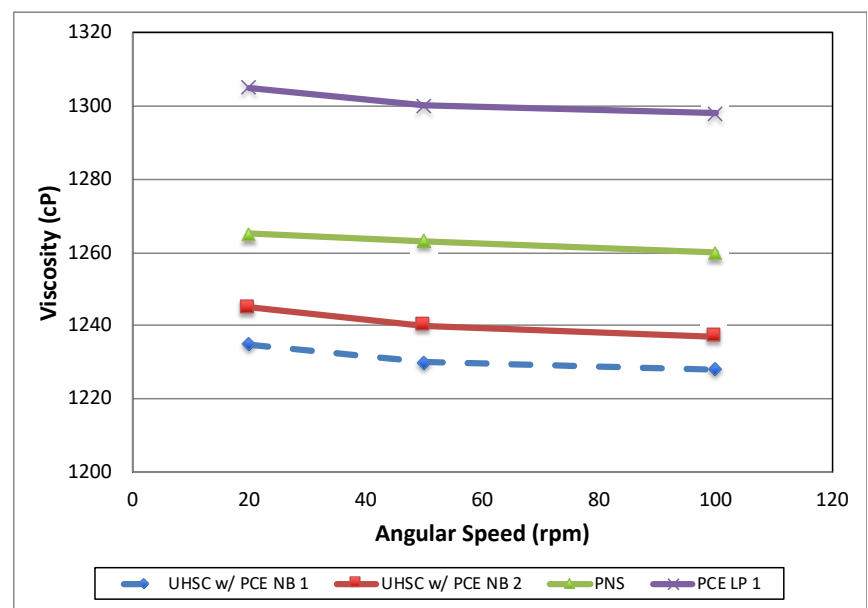

Figure 2. Viscosity of UHSC made with four superplasticizers at a w/cm $=0.20$.

As seen in both Figs 2 and 3, the viscosity of the UHSC is much higher than that of simply the superplasticizers by themselves. Although the viscosity increased, in general, the amount is not as high as expected for conventional concrete, as the UHSC mixtures contain only fine sand (no coarse aggregate), cement, and high amounts of silica fume. Silica fume is the finest sized component in the mixture with a vary spherical shape, which increases the flowability of the mixture, as compared to conventional concretes. It is observed between Figs 2-3 that the four different superplasticizers have an effect on the viscosity of the UHSC mixtures across the three angular speeds. It appears as though that there is a correlation between the viscosity of simply the superplasticizer and its impact to the UHSC mixtures, as can be seeing across Figs 2-3. The correlation is that the lower viscosity superplasticizers produced the lowest viscosity UHSC mixture and the highest produced the highest. In other words, the lowest to highest superplasticizer viscosities ranked PCE NB-1, PCE NB-2, PNS, then PCE LP 1. That is also the order from lowest to highest of the UHSC mixtures made with each superplasticizer, for both $\mathrm{w} / \mathrm{cm}$ ratios. The results also show that the viscosity increases slightly with a lower w/cm, which is expected. Although there is an increase in 
the amount of superplasticizer, the viscosity still changed, by a small amount. These results are consistent with the mortar flow test as well. It is also observed that the particular densities, $\mathrm{pH}$ values, and other properties as reported in Table 2 have no impact on the viscosity of the superplasticizers. For example, PCE LP had the same density as PCE NB but PCE LP yielded the highest viscosity. It can generally be observed that the properties in Table 3 are all relatively close to each other and the primary property effecting the viscosity of the concretes is the viscosity of the superplasticizer.

All concrete sample compressive strength measurements were collected according to BS EN 12390-3-2009 [10] standard, which is a British standard used for 50-mm (2-in.) concrete cubes. Steel plates were slightly coated with a lubricant and each test sample was placed between the platens and loaded into the center of the load frame. The screeted face of the cube was not placed in contact with the platens during analysis. This produced a load on the smoother cube surface and allowed more perpendicular contact with the plate. The results of the compression testing can be seen in Fig. 4.

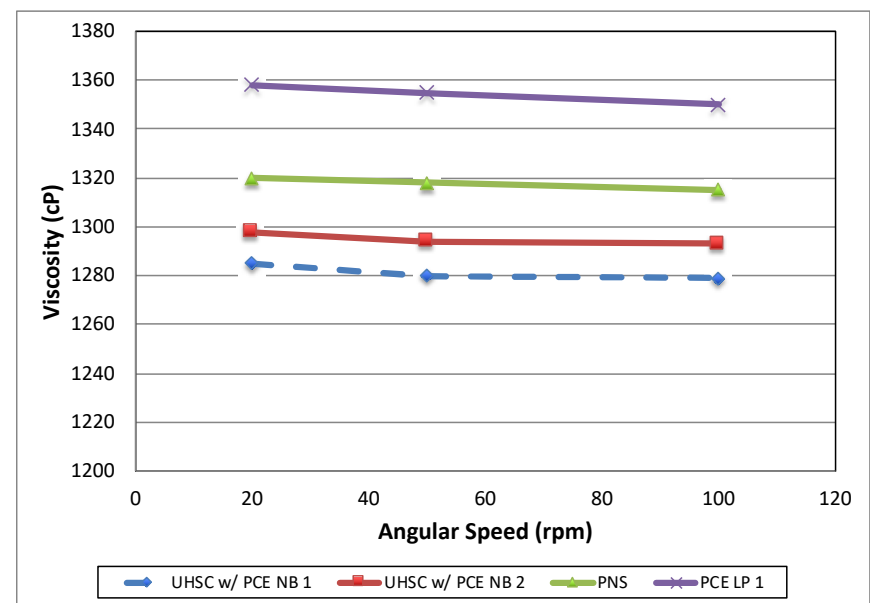

Figure 3. Viscosity of UHSC made with four superplasticizers at a w/cm $=0.15$.

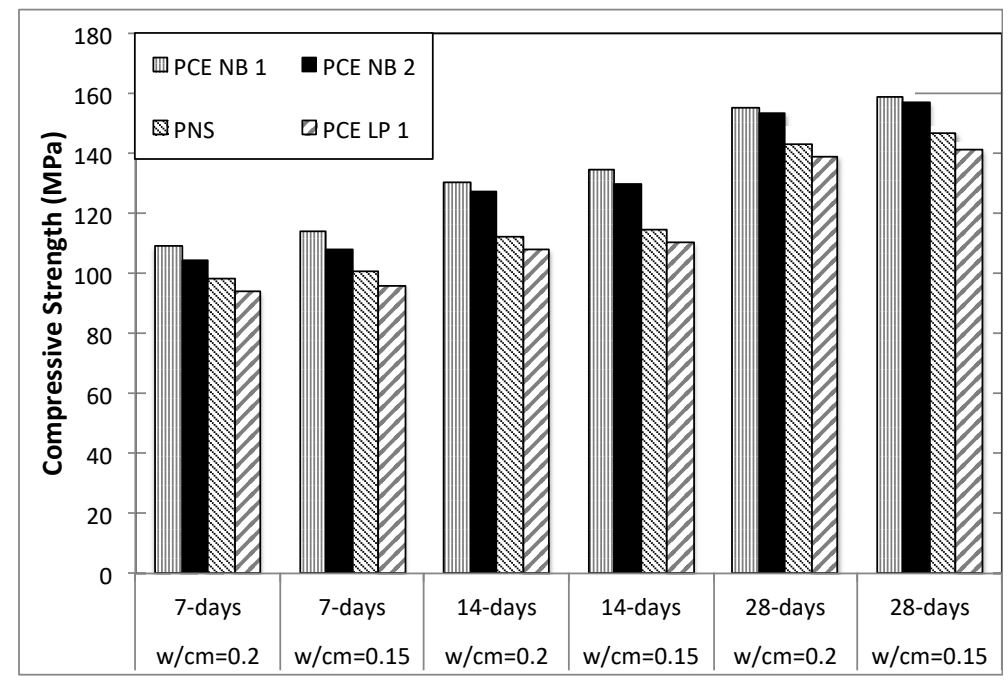

Figure 4. Compressive strength results.

The results of the compression strength testing demonstrate as expected, results, that are consistent with the viscosity and spread tests previously discussed. Specifically, the compressive strengths increase with an increase in age. Additionally, the strengths increase with a decrease in $\mathrm{w} / \mathrm{cm}$. The maximum strength achieved was 158.9MPa produced by the 28-day, $0.15 \mathrm{w} / \mathrm{cm}$, PCE NB 1 mixture. The lowest compressive strength obtained was the 7-day, $0.20 \mathrm{w} / \mathrm{cm}$, PCE LB with a strength of 93.9MPa. However, this should be noted as a sufficiently high compressive strength when compared to conventional concrete. It is also observed that the PCE NB 1 consistently produced the highest results with the PCE NB 2 shortly behind. These results were followed by the PNS and the PCE LP for the lowest compressive strengths. It can also be observed that PCE LP 1 always had the lowest performing strengths, which also had the highest superplasticizers viscosity as well as the highest UHSC viscosity. 
In fact, all of the compressive strength results have an inverse correlation to the spread test and viscosity measurements of both the superplasticizers by themselves and the UHSC mixtures. In other words, the superplasticizer and mixture with the lowest viscosity (i.e. more flowable) produced the highest compressive strengths. This result is expected as the only thing that is changing across these mixtures is the superplasticizer itself, which only impacts the flowability. The flowability allows for better compaction of the mixture, which results in a denser specimen/product. This ultimately results in a slightly higher compressive strength performance. A more flowable mixture also results in an easier pumped and finished product. It can also be gleaned from this data that the primary impact of the superplasticizers on the concrete is primarily due to the viscosity of the superplasticizer, which is consistent with the literature and previously discussed results on viscocity of the concretes.

\section{Conclusions}

The results from this study show the impact of four various superplasticizers on UHSC mixtures. A total of four various superplasticizers were used from two different companies. Four different types of superplasticizers were used; two different PCE based superplasticizers from a leading manufacturer, one PNS superplasticizer, and one PCE superplasticizer, both of which were provided by a local chemical provider. The two name brand products produced the lowest viscosities, highest mortar spread, and the highest compressive strengths. Whereas the two local provider superplasticizers results were the opposite, with the highest viscosity, which produced a lower mortar spread, and a lower compressive strength. The results from the viscosity testing of just the superplasticizers and the UHSC mixtures ultimately led to the final results of the mortar spread test to assess the workability of the concretes. Such that the two locally provided superplasticizers had the two highest viscosities, which produced a lower mortar spread in the concrete, which in turn produced a less workable concrete. These less workable concretes also produced lower compressive strengths, likely due to a lower hardened density and less hydration of all cementing particles. The results from this study can ultimately led to better knowledge regarding UHSC and specifically the impact of various superplasticizers.

\section{References}

[1] ASTM C494. Standard specifications for admixtures in concrete. American Society for Testing and Materials, USA;2009.

[2] Mardani-Aghabaglou A, Tuyan M, Yılmaz G, Arı̈z Ö, Ramyar K. Effect of different types of superplasticizer on fresh, rheological and strength properties of self-consolidating concrete. Construction and Building Materials. 2013;47:1020-1025.

[3] Collepardi M, Monosi S, Valenti M. Optimization of super-plasticizer type and dosage in fly ash and silica fume concretes. American Concrete Institute. 1989;119: 425-444.

[4] ASTM C150. Standard specification for portland cement. American Society for Testing and Materials, USA; 2009.

[5] Collepardi S, Coppola L, Toli R, Colepardi M. Mechanical properties of modi-fied reactive powder concrete. Mechanical Properties of Modified Reactive Powder Concrete; 2007.

[6] Diliand AS, Santhanam M. Investigations on reactive powder concrete: A developing ultra high-strength technology. Indian Concrete Journal. 2004;78(4):33-38.

[7] Shaheen E, Shrive NG. Optimization of mechanical properties and durability of reactive powder concrete. ACI Materials Journal. 2006;103(6):444-451.

[8] Aguayo F, Torres A, Talamini T, Whaley K. Investigation into the heat of hydration and alkali silica reactivity of sustainable ultrahigh strength concrete with foundry sand. Advances in Materials Science and Engineering. 2017;2017. Article ID 2096808.

[9] NF EN12390-3. Testing hardened concrete - Part 3: Compressive strength of test specimens; 2003.

[10] ASTM Standard C 109-16a (2016). Standard test method for compressive strength of hydraulic cement mortars (Using 2-in. or [50-mm] cube specimens). West Conshohocken, Pa, USA; 2016.

[11] ASTM C1437. Standard test method for flow of hydraulic cement mortars. ASTM International. ASTM Standard C 39-15a (2015), West Conshohocken, Pa, USA; 2015. 